\title{
Long-Term Efficacy of a Mini-Course in Radiation-Reducing Techniques in Invasive Cardiology
}

\section{Langzeitwirksamkeit eines Minikurses in strahlenreduzierender Arbeitsweise in der invasiven Kardiologie}

Authors

Affiliations
E. Kuon ${ }^{1}$, K. Empen ${ }^{2}$, K. Weitmann ${ }^{3}$, A. Staudt ${ }^{4}$, A. Hummel ${ }^{2}$, M. Dörr², T. Reffelmann², W. Hoffmann ${ }^{3}$, S. B. Felix ${ }^{2}$

Abteilung für Kardiologie, Klinik Fränkische Schweiz, Ebermannstadt

Abteilung für Innere Medizin B, Ernst-Moritz-Arndt Universität, Greifswald

Institut für Versorgungsmedizin, Ernst-Moritz-Arndt Universität, Greifswald

${ }^{4}$ Abteilung für Kardiologie und Angiologie, Helios Kliniken, Schwerin
Key words

- radiation safety

- coronary angiography

- radiography

- fluoroscopy

- education

- QA/QC eingereicht 11.12.2012

akzeptiert 7.3.2013

\section{Bibliography}

DOI http://dx.doi.org/

10.1055/s-0033-1335323

Published online: 21.5.2013

Fortschr Röntgenstr 2013; 185 :

720-725 @ Georg Thieme

Verlag KG Stuttgart · New York . ISSN 1438-9029

\section{Correspondence Herr Dr. Eberhard Kuon \\ Kardiologie, Klinik Fränkische Schweiz \\ Feuersteinstrasse 2 \\ 91320 Ebermannstadt Germany \\ Tel.: ++ 49/(0)91 94/55252 \\ Fax: ++ 49/(0)91 94/554399 \\ eberhard.kuon@gmx.de}

\section{Zusammenfassung}

v

Ziel: Validierung der Langzeitwirksamkeit eines 90-minütigen Minikurses in strahlenreduzierender Arbeitstechnik in der invasiven Kardiologie.

Material und Methoden: Vor, 2 Monate und 2 Jahre nach dem Minikurs (Periode I, II und III) wurden folgende Dosisparameter analysiert, erhoben durch 7 Kardiologen im Verlauf von je 10 Koronarangiografien: Dosisflächenprodukt (DFP), radiografischer und fluoroskopischer DFP-Anteil, Anzahl radiografischer Bilder und Serien, und Durchleuchtungszeit.

Ergebnisse: In Periode I und II betrug das mediane Patienten-DFP 31,4 bzw. 15,8 Gy $\times \mathrm{cm}^{2}$ und sank bis Periode III nochmals auf $8,5 \mathrm{~Gy} \times \mathrm{cm}^{2}$. Dieser Langzeiteffekt war verbunden mit einer kürzeren medianen Durchleuchtungszeit (180, 172 bzw. 120 Sekunden), weniger $(12,12,10)$ und kürzeren (57, 52, 45 Bilder/Serie) Serien, sowie besserer Einblendung und Beschränkung auf hinreichende Bildqualität: radiografisches DFP/Bild (28,7, 17,0 bzw. $\left.18,4 \mathrm{mGy} \times \mathrm{cm}^{2}\right)$ wie fluoroskopisches DFP/ Sekunde $\left(45,7,24,2\right.$ bzw. 10,0 $\left.\mathrm{mGy} \times \mathrm{cm}^{2}\right)$ sanken signifikant. Die multivariate Regressionsanalyse bestätigte die zunehmende Effektivität des Minikurses von Periode II $(-44,6 \%)$ auf III $(-60,7 \%)$. Gleichzeitig sank der Einfluss der interventionellen Erfahrung der Untersucher (-8,6\% bzw. $-4,9 \%$ pro 1000 Koronarangiografien, jeweils durchgeführt bis zum Kurs). Die Anzahl der Koronarangiografien nach dem Kurs beeinflusste die Langzeitergebnisse nicht.

Schlussfolgerung: Das vorgestellte Kursprogramm ermöglicht im Langzeitverlauf eine signifikante, nachhaltige und fortschreitende Reduktion der Patientendosis in der diagnostischen Koronarangiografie. Eine selbstkontrollierende Dokumentation relevanter Dosisparameter ist bestens geeignet, individuelle strahlenhygienische Bemühungen der Untersucher zu überwachen und zu verbessern.

\section{Abstract \\ $\nabla$}

Purpose: To validate the long-term efficacy of a 90-min. educational mini-course in less-irradiating cardiac interventional techniques.

Materials and Methods: Before, two months after, and two years after the mini-course (periods I, II, and III), we analyzed the following radiation dose parameters for ten coronary angiographies (CA), performed by each of 7 cardiologists: total dosearea product (DAP), radiographic and fluoroscopic DAP fractions, number of radiographic frames and runs, and fluoroscopy time.

Results: The median patient DAP for periods I, II and III was $31.4,15.8$ and $8.5 \mathrm{~Gy} \times \mathrm{cm}^{2}$, respectively. The long-term effect was related to shorter median fluoroscopy times $(180,172$, and $120 \mathrm{~s})$, shorter (57, 52, and 45) and fewer $(12,12$, and 10) radiographic runs, consistent collimation and restriction to an adequate image quality. Both radiographic DAP/frame (28.7, 17.0, and $18.4 \mathrm{mGy} \times \mathrm{cm}^{2}$ ) and fluoroscopic DAP/second (45.7, 24.2, and $\left.10.0 \mathrm{mGy} \times \mathrm{cm}^{2}\right)$ decreased significantly. The multivariate linear regression analysis confirmed the increasing efficacy of the mini-course itself (-44.6 and $-60.7 \%)$, and revealed a decreasing influence of the interventionalist's experience $(-8.6 \%$ and $-4.9 \%$ per 1,000 CAs, lifelong performed until the mini-course). The number of CAs performed after the mini-course did not influence the long-term DAP results.

Conclusion: The presented educational minicourse allows a significant, long-lasting, and apparently ongoing reduction of patient radiation exposure due to CA. A self-surveillant documentation of relevant radiation parameters is well suited to monitor and improve each operator's individual long-term radiation-reducing efforts. 


\section{Introduction}

\section{$\nabla$}

The first warnings regarding the "strongly delayed appearance of serious effects" of radiation exposure on tissue were published as early as 1896 [1]. In 1925, Groedel, the founder of both the German Cardiac Society and the American College of Cardiology, summarized the following factors as playing deleterious roles in conjunction with X-ray applications: excessively long fluoroscopic examinations, short focus-skin distances, insufficient filtering of the X-ray beam, and excessive numbers of radiographs made by insufficiently trained operators [2]. These problems have apparently not yet been entirely resolved in invasive cardiology. Current publications from the International Commission on Radiation Protection (ICRP) point out that unfortunately many interventionalists are not aware of the potential for injury from cardiac procedures, their occurrence, or the simple methods for decreasing their incidence by utilizing dose control strategies [3].

The mean dose-area product (DAP) received by patients from coronary angiography (CA) and percutaneous coronary intervention (PCI) is high and typically varies to an extremely great degree in invasive cardiology: i.e., $16-106 \mathrm{~Gy} \times \mathrm{cm}^{2}$ and $34-191 \mathrm{~Gy} \times \mathrm{cm}^{2}$, respectively $[4,5]$. Actual median (mean) reported levels for DAPs of 741,238 procedures registered from 842 German catheterization laboratories in 2011 were 23.0 (31.3) $\mathrm{Gy} \times \mathrm{cm}^{2}$ for CA and 50.3 (65.9) $\mathrm{Gy} \times \mathrm{cm}^{2}$ for combined PCI [6]. A DAP of $100 \mathrm{~Gy} \times \mathrm{cm}^{2}$ applied in one constant tube angulation to an area of the patient's skin of approximately $40 \mathrm{~cm}^{2}$ will induce a calculated entrance skin air kerma of $2.5 \mathrm{~Gy}$ and - including backscatter - a skin entrance dose of approximately $3.0 \mathrm{~Gy}$. In $3 \%$ of coronary interventions the maximum skin dose exceeded the threshold for deterministic skin erythema (>2 Gy) [7] and even deep-skin and musculocutaneous injury (>15 Gy) in conjunction with complex coronary interventions may result $[3,8,9]$. Recent results suggest that hazards include altered cellular redox balance [10], somatic DNA damage $[10,11]$, and radiation-induced cancer $[12,13]$ in patients and chronically exposed physicians. In an international survey the average number of cases of radiation-induced cancer per million CAs was calculated as 280 [14]. For these reasons we have developed and validated effective dose-reduction techniques [4, 15] and, without negative implications on diagnostic accuracy and procedural outcome, have achieved a mean patient DAP of $4.2 \mathrm{~Gy} \times \mathrm{cm}^{2}$ for elective CA [16] and $6.7 \mathrm{~Gy} \times \mathrm{cm}^{2}$ for one-vessel PCI [17], equivalent to effective doses of 0.8 and $1.3 \mathrm{mSv}$, respectively [5].

To "Encourage Lower-Irradiation Cardiac Interventional Techniques" was the primary goal of our ELICIT initiative: the presented mini-course in radiation-reducing techniques that has proved successful and has been validated as effective in the clinical routine [18]. Two years after this training program, we investigated the long-term efficacy of this mini-course and analyzed independent influencing factors such as operators' interventional experience and patient body mass index (BMI), sex, and age.

\section{Methods}

$\nabla$

\section{Definitions}

Entrance skin dose (unit: Gray $[\mathrm{Gy}]=\mathrm{J} / \mathrm{kg}$ ) is the dose to air in the entrance plane of the patient including backscatter and represents the most appropriate quantity for the characterization of deterministic skin lesions. The dose area product (DAP) is the product of the mean dose in air in a given plane perpendicular to the central beam and the irradiated area at this plane (unit:
Gy $\times \mathrm{cm}^{2}$ ) and is independent of the distance from the X-ray source. The effective dose (ED) is the sum of all weighted dose equivalents of exposed organs in the body (unit: Sievert [Sv]) and characterizes future stochastic cancer risks. DAP-to-ED conversion factors have been calculated to range between 0.18 and $0.22 \mathrm{mSv} / \mathrm{Gy} \times \mathrm{cm}^{2}$ for the thoracic region in adults [5].

\section{Study design and recommendations for radiation-reducing techniques}

All seven interventionalists of the Cardiology Center of Greifswald University, Germany, participated. In study period I, each of them consecutively performed ten elective CAs by femoral access and documented the following radiation dose parameters: total DAP, radiographic $\left(\mathrm{DAP}^{\mathrm{R}}\right)$ and fluoroscopic $(\mathrm{DAP})$ fractions, fluoroscopy time, and the number of radiographic frames and runs. DAPR/ frame and $\mathrm{DAP} /$ second(s) were calculated to demonstrate the efficacy of collimation to the region of interest. Bypass graft controls, significant valve diseases, and emergency catheterizations were excluded, since they are inhomogeneous $[16,17]$. The interactive oral PowerPoint mini-course, a standardized 90-minute workshop, addressed the following dose-reduction principles $[4,15,18]$ :

- Essential radiographic runs and frames

- Consistent collimation, i. e. to the ostial region of interest during intubation of coronary arteries

- Fluoroscopy-free collimation or intermittent fluoroscopy by short pedaling

- Adequately low-level acquisition modes

- Less irradiating angulations

- Reduced magnification and full inspiration during radiography whenever possible

- Long source-to-skin and short patient-to-detector distances

- Sufficiently well-rested operators

Periods II and III consisted of repeated measurements approximately two months and two years after the mini-course, with short-term and long-term median (interquartile ranges) results of 67 (54-88) and 654 (603-711) days, respectively ( Table 1$)$. All patients and interventionalists were encoded. Each interventionalist estimated the number of lifelong CAs performed prior to the mini-course as a parameter of his/her individual interventional experience ( $\bullet$ Fig. 1), used the same equipment before and after the mini-course, received feedback in writing about his/her individual results at baseline, but obtained no further in-house training.

\section{Equipment}

We used a digital, single-arm undercouch tube flat panel system (AXIOM Artis dFC; Siemens AG, Erlangen, Germany) with an antiscatter grid and a $2.9-\mathrm{mm}$ aluminum filter equivalent installed in the X-ray beam. Based on the previous fluoroscopic image, an automatic algorithm determined the thickness of additional variable copper filters within the range of 0.2 to $0.9 \mathrm{~mm}$ for fluoroscopy and 0.0 to $0.9 \mathrm{~mm}$ for radiography. With a focus-image detector distance of $1.2 \mathrm{~m}$, a $25-\mathrm{mm}$ thick aluminum absorber and a 20-cm detector field format, the detector entrance dose rates were $0.029 \mu \mathrm{Gy} /$ pulse (15 pulses/s) for fluoroscopy and $0.170 \mu \mathrm{Gy} /$ frame for radiographic documentation (15 frames/s). The DAP was measured by a light transparent ionization chamber (K1-S Axiom, PTW, Freiburg, Germany), which was calibrated in-situ. Uncertainty varied between $0 \%$ in $90^{\circ}$ left lateral oblique (LAO) angulation and $<10 \%$ overestimation of the real DAP in postero-anterior (PA) angulation (total uncertainty $<15 \%$ ). All technical devices remained unchanged during the study, i.e. did not receive any upgrade with respect to radiation dose parameters. 
Table 1 Median (interquartile range) radiation dose parameters before (I), two months after (II) and approx. two years after (III) the mini-course in radiationreducing techniques. DAP: dose area product; DAPR, F: radiographic, fluoroscopic DAP; statistical significance at 0.05/3 level (Mann-Whitney U test and Bonferroni adjustment) and ${ }^{*} 0.05$ level ( $X^{2}$ test).

Tab. 1 Mediane (interquartiler Bereich) Strahlendosisparameter vor (I), 2 Monate (II) sowie ca. 2 Jahre (III) nach dem Minikurs in strahlenreduzierender Arbeitsweise. DAP, Dosisflächenprodukt; DAPR, F, radiografisches bzw. fluoroskopisches Dosisflächenprodukt; statistische Signifikanz ab 0,05/3 Niveau (MannWhitney U Test und Bonferroni Adjustierung) und ${ }^{*} 0,05$ Niveau ( $X^{2}$ Test).

\begin{tabular}{|c|c|c|c|c|c|c|}
\hline & \multicolumn{6}{|c|}{ patient dose parameters } \\
\hline & & & & II vs. I & III vs. II & III vs. I \\
\hline & period I & period II & period III & p-value & p-value & p-value \\
\hline operators [n] & 7 & 7 & 7 & & & \\
\hline patients [n] & 70 & 70 & 70 & & & \\
\hline age [years] & $63.3(52.6-68.9)$ & $64.9(54.3-70.3)$ & $65.4(56.5-71.4)$ & 0.3669 & 0.7373 & 0.1978 \\
\hline female [\%] & 34.3 & 41.4 & 52.9 & $0.3836^{*}$ & $0.1756^{*}$ & $0.0267^{*}$ \\
\hline BMI $\left[\mathrm{kg} / \mathrm{m}^{2}\right]$ & $27.1(24.9-30.0)$ & $27.6(24.6-30.1)$ & $26.8(24.2-30.4)$ & 0.8775 & 0.7169 & 0.5923 \\
\hline $\mathrm{DAP}\left[\mathrm{Gy} \times \mathrm{cm}^{2}\right]$ & $31.4(20.0-40.6)$ & $15.8(10.3-22.9)$ & $8.5(6.3-13.0)$ & $<0.0001$ & $<0.0001$ & $<0.0001$ \\
\hline $\operatorname{DAP}^{R}\left[G y \times \mathrm{cm}^{2}\right]$ & $19.7(13.0-27.8)$ & $11.1(6.6-15.4)$ & $7.5(4.8-11.7)$ & $<0.0001$ & 0.0123 & $<0.0001$ \\
\hline $\operatorname{DAPF}\left[G y \times \mathrm{cm}^{2}\right]$ & $8.0(5.0-13.0)$ & $4.5(2.0-9.5)$ & $1.3(0.7-2.0)$ & 0.0003 & $<0.0001$ & $<0.0001$ \\
\hline radiographic frames [n] & $680(563-751)$ & $633(537-751)$ & $419(356-521)$ & 0.0452 & $<0.0001$ & $<0.0001$ \\
\hline radiographic runs [n] & $12(10-14)$ & $12(11-14)$ & $10(8-12)$ & 0.4175 & $<0.0001$ & $<0.0001$ \\
\hline frames/run [n] & $57(53-65)$ & $52(45-59)$ & $45(40-51)$ & 0.0003 & $<0.0001$ & $<0.0001$ \\
\hline fluoroscopy time [s] & $180(126-306)$ & $172(120-324)$ & $120(82-174)$ & 0.8955 & $<0.0001$ & $<0.0001$ \\
\hline DAPR/frame $\left[\mathrm{mGy} \times \mathrm{cm}^{2}\right]$ & $28.7(21.2-37.7)$ & $17.0(11.4-23.2)$ & $18.4(12.3-25.1)$ & $<0.0001$ & 0.4748 & $<0.0001$ \\
\hline $\mathrm{DAP}^{\mathrm{F}} /$ second $\left[\mathrm{mGy} \times \mathrm{cm}^{2}\right]$ & $45.7(31.9-51.5)$ & $24.2(14.5-35.7)$ & $10.0(6.7-16.7)$ & $<0.0001$ & $<0.0001$ & $<0.0001$ \\
\hline
\end{tabular}

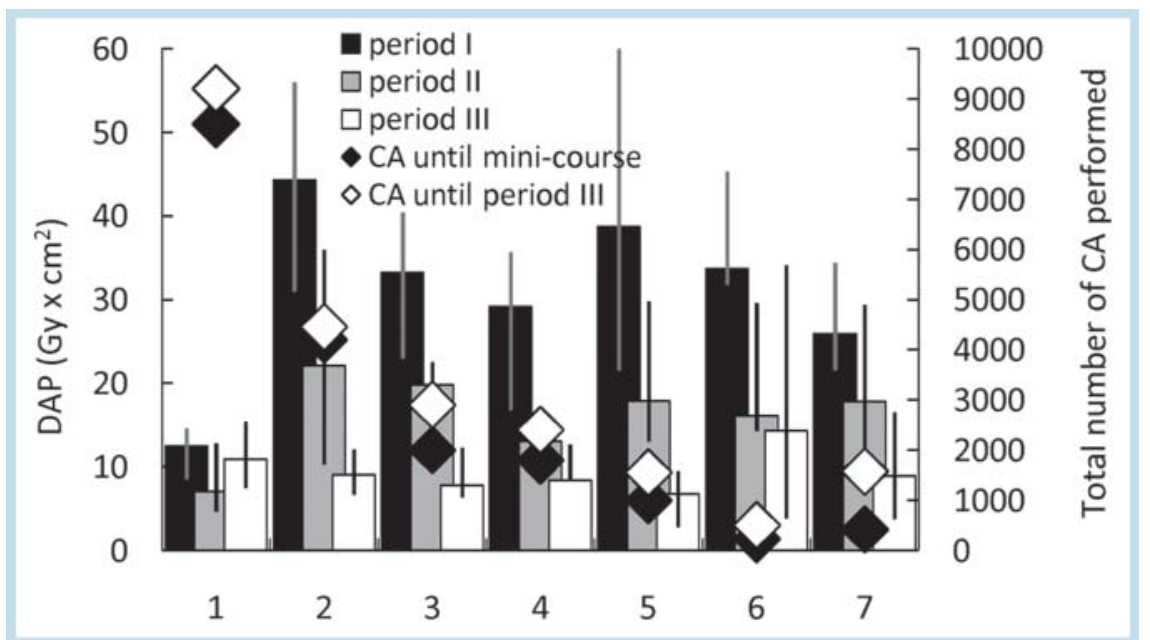

Fig. 1 Median (interquartile range) patient dose-area products (DAP), resulting from ten coronary angiographies (CA) performed by each of seven interventionalists before, two months after, and two years after (periods I, II and III) the mini-course in radiation-reducing techniques. The operators' lifelong interventional experience is indicated by the number of performed CAs with respect to the time of the mini-course and the time two years later (black and white rhombi).
Abb. 1 Mediane (Interquartilbereich) Patienten-Dosisflächenprodukte von jeweils 10 Koronarangiografien, durchgeführt von 7 Interventionalisten unmittelbar vor, 2 Monate sowie 2 Jahre (Periode I, II und III) nach einem Minikurs in strahlenreduzierender Arbeitstechnik. Die interventionelle Untersuchererfahrung ist charakterisiert durch die Anzahl der bislang durchgeführten Koronarangiografien bis zum Zeitpunkt des Kurses sowie 2 Jahre später (schwarze und weiße Rauten).

\section{Statistical analysis}

Values were expressed as median and interquartile range (IQR: 25-75th percentile). Three groups (periods [p] I, II, and III) of non-normally distributed variables were analyzed by the Kruskal-Wallis test. A two-tailed p-value of $<0.05$ was regarded as significant to prove the variables to be different. Paired comparisons (period II vs. I, III vs. II, and III vs. I) of significant results were performed using the Mann-Whitney U test. In this case, a Bonferroni adjustment of significance level was required, i. e., p-values lower than $0.05 / 3$ were considered statistically significant. Analy- ses were performed using the software SAS (V 9.1, SAS Institute Inc., Cary, NC, USA). For categorical data, frequencies were compared by the $x^{2}$ test.

To rule out biasing effects, we performed multivariate linear regression analysis to adjust for patient age, sex, and BMI, as well as for the operator's interventional experience prior to and two years after the mini-course. The various periods were coded dichotomously for the short-term (period I vs. period II) and longterm (period I vs. period III) analyses. Normal distribution of residuals was tested using the Shapiro-Wilk test at a significance 


\begin{tabular}{|c|c|c|c|c|}
\hline \multirow[b]{2}{*}{ short-term results } & \multicolumn{4}{|c|}{ specific influence of the } \\
\hline & mini-course ${ }^{1}$ & p-value & operator's experience ${ }^{2}$ & p-value \\
\hline DAP & $-44.6 \%$ & $<0.0001$ & $-8.6 \%$ & $<0.0001$ \\
\hline DAPR & $-47.5 \%$ & $<0.0001$ & $-7.7 \%$ & $<0.0001$ \\
\hline DAPF & $-44.7 \%$ & $<0.0001$ & $-12.2 \%$ & $<0.0001$ \\
\hline radiographic frames & $-10.5 \%$ & 0.0072 & $-4.9 \%$ & $<0.0001$ \\
\hline frames/run & $-11.4 \%$ & $<0.0001$ & $-1.0 \%$ & 0.0170 \\
\hline fluoroscopy time & $+0.5 \%$ & 0.9660 & $-2.0 \%$ & 0.2905 \\
\hline DAPR/frame & $-41.3 \%$ & $<0.0001$ & $-2.0 \%$ & 0.0549 \\
\hline \multicolumn{5}{|l|}{ long-term results ${ }^{3}$} \\
\hline DAP & $-60.7 \%$ & $<0.0001$ & $-4.9 \%$ & 0.0033 \\
\hline DAPR & $-50.6 \%$ & $<0.0001$ & $-3.9 \%$ & 0.0186 \\
\hline DAPF & $-82.2 \%$ & $<0.0001$ & $-8.6 \%$ & $<0.0001$ \\
\hline radiographic frames & $-27.3 \%$ & $<0.0001$ & $-3.9 \%$ & $<0.0001$ \\
\hline frames/run & $-35.1 \%$ & $<0.0001$ & $-1.0 \%$ & 0.0791 \\
\hline fluoroscopy time & $-27.7 \%$ & 0.0663 & $-3.9 \%$ & 0.0171 \\
\hline $\mathrm{DAP}^{\mathrm{R}} /$ frame & $-32.0 \%$ & 0.0026 & $-1.0 \%$ & 0.6825 \\
\hline
\end{tabular}

Table 2 Relative short and longterm influence of the mini-course and of the operator's experience prior to the mini-course (per 1,000 coronary angiographies).

Tab. 2 Relativer Kurz- und Langzeiteffekt des Minikurses sowie der Untersuchererfahrung bis zum Minikurs (pro 1000 Koronarangiografien).

BMI: body mass index; DAP: dose area product; DAPR,F: radiographic, fluoroscopic DAP.

BMI, Body Mass Index; DAP, Dosisflächenprodukt; DAPR,F, radiografisches bzw. fluoroskopisches Dosisflächenprodukt.

1 adjusted for operator's experience prior to mini-course and patient BMI, sex and age

adjustiert für Untersuchererfahrung bis zum Minikurs sowie BMI, Geschlecht und Alter der Patienten

2 adjusted for period and patient BMI, sex and age

adjustiert für Beobachtungszeitraum sowie BMI, Geschlecht und Alter der Patienten

${ }^{3}$ adjusted additionally for experience after mini-course according to absolute values

zusätzlich adjustiert für Untersuchererfahrung nach dem Minikurs, entsprechend jeweils den Absolutwerten

level of 0.1. Only the variable radiographic runs for the short-term results fulfilled the associated required assumption. In order to guarantee correct statistical conditions for multivariate analysis, $\log (\mathrm{ln})$ transformation or square root (sqrt) transformation was used for dependent original variables of regression models that did not fulfill the normality assumption. The relative variations of various dose parameters multivariately adjusted for the respective influencing variables were obtained by means of exponential retransformation of the log regression coefficients ( $\bullet$ Table 2 ).

\section{Results \\ $\nabla$}

\section{Short-term results}

Short-term benefits of our mini-course were predominantly due to consistent collimation to the region of interest. Accordingly, the radiographic $\mathrm{DAP} / \mathrm{R} /$ frame and the fluoroscopic $\mathrm{DAP}^{\mathrm{F}} / \mathrm{s}$ significantly decreased by $41 \%$ and $47 \%$, respectively, i. e., from 28.7 to $17.0 \mathrm{mGy} \times \mathrm{cm}^{2}$ and from 45.7 to $24.2 \mathrm{mGy} \times \mathrm{cm}^{2}$, respectively. Consequently, the median radiographic and fluoroscopic DAPs decreased by $44 \%$ and $47 \%$, respectively, i.e., from 19.7 to $11.1 \mathrm{~Gy} \times \mathrm{cm}^{2}$ and from 8.0 to $4.5 \mathrm{~Gy} \times \mathrm{cm}^{2}$, respectively. The interventionalists slightly shortened radiographic runs, but failed to substantially reduce radiographic frames and fluoroscopy time (ه Table 1).

\section{Long-term results}

The median patient overall DAP decreased significantly from 31.4 to $8.5 \mathrm{~Gy} \times \mathrm{cm}^{2}-$ i. e., a $73 \%$ relative decrease - to a level even significantly below the median short-term dose levels of $15.8 \mathrm{~Gy} \times \mathrm{cm}^{2}$ two months after the mini-course. Radiation-reducing techniques decreased the median radiographic and fluoroscopic DAP by $62 \%$ and $85 \%$ to levels of 7.5 and $1.3 \mathrm{~Gy} \times \mathrm{cm}^{2}$, respectively, and allowed significantly shorter and fewer radiographic runs. The interventionalists maintained the improved radiographic short-term collimation to the region of interest and moreover optimized the fluoroscopic $\mathrm{DAP} / \mathrm{s}$ to $10.0 \mathrm{mGy} \times \mathrm{cm}^{2}$. The long-term median for fluoroscopy time decreased from 180 to 120 s (o Table 1).

\section{Effects of interventional experience, body mass index, age, and sex}

The calculated multivariate linear regression model for the shortterm efficiency of the mini-course yielded results according the following equation between the natural logarithm (ln) of the dependent variable - for example, the DAP - and the independent influencing factors, i.e., the period ([p]: $0=$ period $\mathrm{I}, 1=$ period II), the operator's lifelong experience ([e]: per 1,000 CAs), patient body mass index ([b]: $\left.\mathrm{kg} / \mathrm{m}^{2}\right)$, patient sex ([s]: $0=$ female, $1=$ male $)$ and patient age ([a]: years):

$\operatorname{Ln}(\mathrm{DAP})=1.003+(-0.591 \times \mathrm{p})+(-0.00009 \times \mathrm{e})+(+0.077 \times \mathrm{b})+$ $(+0.203 \times \mathrm{s})+(+0.005 \times \mathrm{a})$

The natural logarithm of DAP for a 54-year-old male patient (BMI $26.4 \mathrm{~kg} / \mathrm{m}^{2}$ ) and for operator's lifelong experience of 1,000 CAs was 3.393 and 2.803 for periods I and II, respectively, equivalent to the expected absolute values for DAP of $29.7 \mathrm{~Gy} \times \mathrm{cm}^{2}$ (exp [3.393]) and $16.5 \mathrm{~Gy} \times \mathrm{cm}^{2}(\exp [2.803])$. Under conditions of constancy of all other variables, the patient DAP for a CA performed in period II was $\exp (-0.591)=0.554(-44.6 \%)$, compared to the DAP in period I, indicating the adjusted relative short-term efficacy of our mini-course ( $\bullet$ Table 2, upper panel). The DAP likewise slightly varied according to $\exp (-0.09)=0.914(-8.6 \%)$ per 1,000 CAs of individual experience ( $\bullet$ Table 2 , upper panel) to exp $(+0.077)=1.080(+8.0 \%)$ per one unit of $\mathrm{kg} / \mathrm{m}^{2} \mathrm{BMI}$ and to exp $(+0.203)=1.225(+22.5 \%)$ for men compared to women.

Adjusted for the operators' experience and patient BMI, sex and age, the patient DAP for a CA performed in period III was exp $(-0.933)=0.393(-60.7 \%)$, compared to the DAP in period I. Likewise, the mini-course yielded a significant beneficial long-term effect on all parameters associated with radiation dose ( $\bullet$ Table 2 , lower panel).

The operator's interventional experience, characterized by the number of lifelong CAs performed prior to the mini-course, in ad- 
dition to the efficacy of the mini-course indeed slightly influenced various dose parameters. Per 1,000 CAs performed prior to the mini-course, the presented regression model revealed long-term decreases of $4.9 \%, 3.9 \%, 8.6 \%, 3.9 \%$, and $3.9 \%$ for DAP, radiographic $\mathrm{DAP}^{\mathrm{R}}$, fluoroscopic $\mathrm{DAP}$, radiographic frames, and fluoroscopy time, respectively ( $\bullet$ Table 2 , right column, lower panel). In contrast to the increasing efficacy of the mini-course over the course of the two years after the mini-course, however, the influence of the operator's experience on all DAP fractions evidently decreased ( $\bullet$ Table 2 ). Our multivariate regression analysis revealed that the latter long-term DAP results were not significantly influenced by the number of CAs performed after the mini-course. All variables for DAP and for dose intensity, but neither the number of radiographic frames and runs nor the fluoroscopy time, were positively associated with patient BMI.

\section{Discussion}

$\nabla$

Our mini-course in radiation-reducing techniques in cardiology is the first such effort to be validated in the clinical routine with respect to long-term efficacy. Without further in-hospital training, the reduction of the median patient DAP was not merely significant and lasting, but apparently ongoing. Whereas the short-term efficacy $[18,19]$ was predominantly due to consistent collimation, the long-term benefits moreover included significant improvements in all radiation-reducing techniques ( $\bullet$ Table 1 ).

Avoidance of lengthy filming - i.e., fewer and shorter (median length $3.0 \mathrm{~s}$ ) radiographic runs - was an essential step towards significant dose reduction. Bypass grafts, late-filling collateral pathways, and low-flow phenomena, however, should be documented by sufficiently longer series. The interventionalists indeed maintained the improved short-term collimation to the region of interest ( $\triangle$ Table 1 ), i. e., the median fluoroscopic DAPF/ second continued to decrease from 24.2 to $10.0 \mathrm{mGy} \times \mathrm{cm}^{2}$. In accordance with current ICRP recommendations [3], the interventionalists obviously reduced the fluoroscopic pulse rate and/ or the detector entrance dose level towards an adequate instead of best-possible fluoroscopic image quality. For constant detector entrance doses and without collimation however, at an anthropomorphic Alderson-Rando phantom the fluoroscopic DAP/s varied according to the special requirements of tube angulation within a range of 12 to $111 \mathrm{mGy} \times \mathrm{cm}^{2}$ [15]. As recommended in our course program, interventionalists should therefore avoid the typical LAO views for the documentation of the bifurcations of the left main stem and the left anterior descending artery in favor of less irradiating caudal and cranial PA views [4, 15].

The multivariate regression models for both short-term and longterm analyses revealed further details. As expected, the BMI, in a range between 7.5 and $9.9 \%$ per $\mathrm{kg} / \mathrm{m}^{2}$, is correlated positively with all DAP fractions, but not with the number and length of radiographic runs. Female gender is correlated to lower DAPR/ frame, which could be interpreted to result from the lower overall bone mass of women and their tendency to postmenopausal osteoporosis.

Over and above the predominant short-term and long-term efficacy of the mini-course, which, according our multivariate linear regression analysis, enabled adjusted DAP reductions of $44.6 \%$ and $60.7 \%$ ( Table 2 ), the operator's interventional experience also slightly but significantly influenced all DAP fractions and the number of radiographic frames and runs. Per 1,000 CAs individually performed lifelong prior to the mini-course, all DAP frac- tions decreased between $7.7 \%$ and $12.2 \%$ two months after and between merely $3.9 \%$ and $8.6 \%$ to baseline two years after the interventional training ( $\bullet$ Table 2 ). The operators' experience after the mini-course apparently did not influence the patient DAP. Whereas the short-term effect of the operators' lifelong experience manifested itself in terms of fewer radiographic frames and better collimation, an additional but merely slight long-term effect was evidently shorter fluoroscopy times. The presented short-term results accordingly confirm that the predominance of fluoroscopy time as the widely considered criterion for operators' efforts in radiation-reducing techniques should decrease as a logical consequence of the fact that approx. $65-70 \%$ of the total DAP for a CA is due to radiographic acquisition $[4,17]$.

The presented mini-course in radiation-reducing techniques resulted in a considerable long-term reduction in patient DAP in the course of elective CA, predominantly due to the efficacy of the mini-course itself ( $\bullet$ Table 2 ). The resulting median DAP of $8.5 \mathrm{~Gy} \times \mathrm{cm}^{2}$ is far below typical levels of $23.0 \mathrm{~Gy} \times \mathrm{cm}^{2}$ according to the National German Quality Registry [6]. With the use of DAPto-ED conversion factors of approximately $0.20 \mathrm{mSv} / \mathrm{Gy} \times \mathrm{cm}^{2}$, the biologically relevant patient ED decreased in the course of our presented ELICIT study from $4.6 \mathrm{mSv}$ to $1.7 \mathrm{mSv}$ [5]. The additional individual lifetime attributable risk (LAR) of cancer from a coronary intervention generating $40 \mathrm{mSv}$ (equivalent to $200 \mathrm{~Gy} \times \mathrm{cm}^{2}$ ) is approximately 0.20 to $1.00 \%$ [8]. ED values of multi-slice computed tomography coronary angiography (CTCA) with the use of retrospective ECG-gating - representing noninvasive CA - are reported to vary from 8 to $28 \mathrm{mSv}[4,20,21]$ and yield the considerable calculated LAR of cancer incidence for a representative 50 -year-old subject with a range between 0.10 and $0.17 \%$ for males and between 0.23 and $0.37 \%$ for females [22]. The use of automatic dose control reduced the ED in chest scans by $36 \%$ [23], and in conformity with actual recommendations [24], ECG-triggered, singleand two-heartbeat CTCA enabled lower EDs of 2.2 to $8.6 \mathrm{mSv}$, without affecting diagnostic performance [21, 25-27]. For the specific subgroup of non-obese patients with a low and stable heart rate, furthermore, values even on the submillisievert level for CTCA have been achieved [28]. ED determined from Monte Carlo simulations of chest CT, however, were reported to underestimate in-vivo ED substantially for both volume and helical CTCA [25].

Several limitations to this study are worthy of discussion. The lower-irradiating tube angulations recommended in our course program were proved effective merely for the specific intervention of elective coronary angiography. They need to be questioned and undeniably are not transferrable to the broad variety of fluoroscopy-guided radiological interventions at diverse vascular regions and organs of interest all over the human body. For iliac, femoral and peripheral vascular interventions, it is a consistent postero-anterior (PA) tube angulation that ensures patient diameters as low as reasonably achievable and consequently should be favored over both cranio-caudal PA views and oblique lateral views. Alterations of tube angulation during interventions at hepatic vessels or the biliary system will not considerably reduce the time-adjusted radiation intensity. In addition, the DAPto-ED conversion factors for the abdominal and pelvis regions are higher than presented here for the cardiac region, and amount to approx. 0.26 and $0.29 \mathrm{mSv} / \mathrm{Gy} \times \mathrm{cm}^{2}$, respectively [29]. Furthermore, all coronary angiographies were performed using a modern flat panel catheterization system of one manufacturer, which, in contrast to former image intensifier systems, allowed variable pulse rates and detector entrance dose levels in the clinical routine. 
The presented mini-course in radiation-reducing techniques in cardiology is the first validated effort that allows in the clinical routine a significant, lasting, and apparently ongoing reduction of patient radiation exposure due to invasive CA to levels far below typical values in modern catheterization laboratories and comparable to or even below those achieved by new techniques in CTCA. The documentation of DAPF and DAPR and of the number of radiographic frames in addition to fluoroscopy time and total DAP is well suited to monitor - by self-surveillance or by supervisory authorities - each operator's individual long-term efforts to decrease radiation exposure. The individual strategy of our minicourse conclusively allows considerable occupational dose reductions, confirms recent recommendations on training and supervision in those techniques $[8,30,31]$, and indeed promises to be more efficient than current directives for simple documentation and regulative control of upper-limit reference levels for DAP and fluoroscopy time at cardiac centers [6].

\section{References}

1 Thomson E. Strong effects by X-rays on tissue. Electrical Engineering 1896; $22: 534$

2 Groedel FM, Lininger H, Lossen $H$ (eds). Materialsammlung der Unfälle und Schäden in Röntgenbetrieben. Hamburg: Lucas, Gräfe \& Sillem; 1925

3 ICRP. Recommendations of the International Commission on Radiological Protection. Ann ICRP 2007; 37: 1-332

4 Kuon E. Radiation exposure in invasive cardiology. Heart 2008; 94: 667-674

5 Pantos I, Patatoukas G, Katritsis DM et al. Patient radiation doses in interventional cardiology procedures. Curr Cardiol Rev 2009; 5: 1-11

6 AQUA-Bundesauswertung 2011 - Koronarangiographie und perkutane Koronarintervention (PCI). Qualitätsindikatoren. AQUA-Institut für angewandte Qualitätssicherung und Gesundheitsforschung; 31.05 2011, S 62 http://www.sqg.de/downloads/Bundesauswertungen/ 2011/bu_Gesamt_21N3-KORO-PCI_2011.pdf Accessed November 15,2012

7 Bogaert E, Bacher K, Lemmens K et al. A large-scale multicentre study of patient skin doses in interventional cardiology: dose-area product action levels and dose reference levels. Br J Radiol 2009; 82: 303-312

8 Hirshfeld JW Jr, Balter S, Brinker JA et al. ACCF/AHA/HRS/SCAI clinical competence statement on physician knowledge to optimize patient safety and image quality in fluoroscopically guided invasive cardiovascular procedures: a report of the American College of Cardiology Foundation/American Heart Association/American College of Physicians Task Force on clinical Competence and Training. Circulation 2005; 111: $511-532$

9 Chambers CE, Fetterly KA, Holzer $R$ et al. Radiation safety program for the cardiac catheterization laboratory. Catheter Cardiovasc Interv 2011; 77: 546-556

10 Russo GL, Tedesco I, Russo M et al. Cellular adaptive response to chronic radiation exposure in interventional cardiologists. Eur Heart J 2012; 33: $408-414$

11 Geisel D, Zimmermann E, Rief M et al. DNA double-strand breaks as potential indicators for the biological effects of ionising radiation exposure from cardiac CT and conventional coronary angiography: a randomized, controlled study. Eur Radiol 2012; 22: 1641-1650

12 Eisenberg MJ, Afilalo J, Lawler PR et al. Cancer risk related to low-dose ionizing radiation from cardiac imaging in patients after acute myocardial infarction. CMAJ 2011; 183: 430-436
13 Roguin A, Goldstein J, Bar Olivier. Brain malignancies and ionising radiation: more cases reported. EuroIntervention 2012; 8: 169-170

14 Berrington de Gonzalez A, Darby S. Risk of cancer from diagnostic X-rays: estimates for the UK and 14 other countries. Lancet 2004; 363: $345-$ 351

15 Kuon E, Dahm JB, Empen K et al. Identification of less irradiating angulations in invasive cardiology. J Am Coll Cardiol 2004; 44: 1420-1428

16 Kuon E, Schmitt M, Dorn C et al. Predialing the number of cinegraphic frames enables an effective patient dose due to coronary angiography of $0.8 \mathrm{mSv}$. Fortschr Röntgenstr 2003; 175: 1706 - 1710

17 Kuon E, Empen K, Rohde D et al. Radiation exposure to patients undergoing percutaneous coronary interventions - Are current reference values too high? Herz 2004; 29: 208 - 217

18 Kuon E, Empen K, Robinson DM et al. Efficiency of a minicourse in radiation reducing techniques: a pilot initiative to encourage less irradiating cardiological interventional techniques (ELICIT). Heart 2005; 91: $1221-1222$

19 Georges JL, Livarek B, Gibault-Genty G et al. Reduction of radiation delivered to patients undergoing invasive coronary procedures. Effect of a programme for dose reduction based on radiation-protection training. Arch Cardiovasc Dis 2009; 102: 821 - 827

20 Mori S, Nishizawa K, Kondo C et al. Effective doses in subjects undergoing computed tomography cardiac imaging with the 256-multislice CT scanner. Eur J Radiol 2008; 65: 442 - 448

21 Hausleiter J, Meyer TS, Martuscelli E et al. Image quality and radiation exposure with prospectively ECG-triggered axial scanning for coronary CT angiography: The multicenter, multivendor, randomized PROTECTION-III study. JACC Cardiovasc Imaging 2012; 5: 484-493

22 Smith-Bindman R, Lipson J, Marcus $R$ et al. Radiation dose associated with common computed tomography examinations and the associated lifetime attributable risk of cancer. Arch Intern Med 2009; 169: 2078 2086

23 Stumpp P, Gosch D, Kühn A et al. Performance of an automatic dose control system for CT: patient studies. Fortschr Röntgenstr 2013; 185 : $144-152$

24 Achenbach S, Barkhausen J, Beer M et al. Konsensusempfehlungen der DRG/DGK/DGPK zum Einsatz der Herzbildgebung mit Computertomographie und Magnetresonanztomographie. Fortschr Röntgenstr 2012; 184: $345-368$

25 Einstein AJ, Elliston CD, Arai AE et al. Radiation dose from single-heartbeat coronary $\mathrm{CT}$ angiography performed with a 320-detector row volume scanner. Radiology 2010; 254: 698-706

26 Zimmermann E, Dewey M. Whole-heart 320-row computed tomography: reduction of radiation dose via prior coronary calcium scanning. Fortschr Röntgenstr 2012; 183: 54-59

27 Chen CM, Liu YC, Chen CC et al. Radiation dose exposure of patients undergoing 320-row cardiac CT for assessing coronary angiography and global left ventricular function. Int J Cardiovasc Imaging 2012; 28 (Suppl 1): 1-5

28 Achenbach S, Marwan M, Ropers $D$ et al. Coronary computed tomography angiography with a consistent dose below $1 \mathrm{mSv}$ using prospectively electrocardiogram-triggered high-pitch spiral acquisition. Eur Heart J 2010; 31: 340 - 346

29 Hart $D$, Jones $D G$, Wall BF. Estimation of the effective dose in diagnostic radiology from entrance surface dose and dose-area product measurements. NRPB-R262 National Radiological Protection Board Chilton Didcot, Oxon OX11 ORQ 1994: 36

30 Miller DM, Vañó E, Bartal G et al. Occupational Radiation Protection in Interventional Radiology: A Joint Guideline of the Cardiovascular and Interventional Radiology Society of Europe and the Society of Interventional Radiology. Cardiovasc Interv Radiol 2010; 33: 230-239

31 Fetterly KA, Mathew $V$, Lennon $R$ et al. Radiation dose reduction in the invasive cardiovascular laboratory. Implementing a culture and philosophy of radiation safety. JACC: Cardiovascular Interventions 2012; 5: $866-873$ 